\title{
THE SEMICENTENNIAL CELEBRATION OF THE AMERICAN MATHEMATICAL SOCIETY- SEPTEMBER 6-9, 1938
}

The year 1938 is a very significant one in the life of the American Mathematical Society: it is the fiftieth anniversary of its birth.

It was in the summer of 1888 that a young man of twentythree, Thomas Scott Fiske by name, returned from a period of study in England with the memory of inspiring afternoons at the London Mathematical Society fresh in his mind, and with an ambition to enjoy similar contacts in New York. By direct invitation he brought together a small group on November 24 of that year, and a month later this group organized itself into the New York Mathematical Society. Within three years the movement had spread widely enough so that it was feasible to begin the publication of a journal, the Bulletin of the New York Mathematical Society. Within three more years the national character of the enterprise became so apparent that the present more suitable names were chosen for both the Society and the Bulletin.

It is customary and seemly for societies, like individuals, to celebrate such anniversaries, to rejoice in the success of the years that are past, and to acquire new enthusiasm for the years ahead. Thus the summer meeting of the American Mathematical Society to be held in New York City in 1938 will be in the nature of a birthday party to celebrate this fiftieth anniversary. Like all successful birthday parties, it will have its moments of rejoicing and good cheer: an afternoon at Jones Beach, perhaps America's finest and certainly its least commercialized seaside resort; a trip up the Hudson to West Point (returning by moonlight) on one of the world's finest river boats, especially chartered for the occasion; the gayest banquet that the entertainment committee can provide; and many other diversions-more, indeed, than any one person can possibly attend.

Like all successful birthday parties, it will have its sentimental moments when honor is paid to those who conceived the Society and nurtured it through its tender years. Absence of such sentiments would be unthinkable, particularly at a gather- 
ing distinguished by the presence of the founder himself and held on the campus of the University which has been so hospitable to the Society since its earliest days.

And like all successful birthday parties, it will have its serious moments: a program of nine invited addresses-by Professors J. W. Alexander, E. T. Bell, G. D. Birkhoff, G. C. Evans, E. J. McShane, J. F. Ritt, J. L. Synge, T. Y. Thomas, and Norbert Wiener; the usual opportunity for the presentation of shorter reports on current research; and ample opportunity for serious discussion on the personal plane.

From all three phases we shall hope to obtain a renewal of inspiration and strength for the coming years; for that splendid record of success which we shall celebrate is at once our greatest heritage and most sobering responsibility.

Thornton C. Fry, Executive Secretary of the Semicentennial Committee 